\title{
Recognising Lung Cancer in Primary Care
}

\author{
Stephen H. Bradley • Martyn P. T. Kennedy $\cdot$ Richard D. Neal
}

Received: October 4, 2018 / Published online: November 29, 2018

(C) The Author(s) 2018

\section{ABSTRACT}

Significant advances in the management of both early and advanced stage lung cancer have not yet led to the scale of improved outcomes which have been achieved in other cancers over the last 40 years. Diagnosis of lung cancer at the earliest stage of disease is strongly associated with improved survival. Therefore, although recent advances in oncology may herald breakthroughs in effective treatment, achieving early diagnosis will remain crucial to obtaining optimal outcomes. This is challenging, as most lung cancer symptoms are non-specific or are common respiratory symptoms which usually represent benign disease. Identification of patients at risk of lung cancer who require further investigation is an important responsibility for general practitioners (GPs). Diagnosis has historically relied upon plain chest X-ray (CXR), organised in response to symptoms. The sensitivity of this modality, however, compares

Enhanced digital features To view enhanced digital features for this article go to https://doi.org/10.6084/ m9.figshare.7334852.

S. H. Bradley $(\bowtie) \cdot$ R. D. Neal

Academic Unit of Primary Care, University of Leeds, Leeds, UK

e-mail: medsbra@leeds.ac.uk

M. P. T. Kennedy

Department of Respiratory Medicine, Leeds

Teaching Hospitals NHS Trust, Leeds, UK unfavourably with that of computed tomography (CT). In some jurisdictions screening highrisk individuals with low dose CT (LDCT) is now recommended. However uptake remains low and the eligibility for screening programmes is restricted. Therefore, even if screening is widely adopted, most patients will continue to be diagnosed after presenting with symptoms. Achieving early diagnosis requires GPs to maintain an appropriate level of suspicion and readiness to investigate in high-risk patients or those with non-resolving symptoms. This article discusses the early detection of lung cancer from a primary care perspective. We outline risk factors and epidemiology, the role of screening and offer guidance on the recognition of symptomatic presentation and the investigation and referral of suspected lung cancer.

Keywords: Cancer diagnosis; Chest X-ray; CT chest; General practitioner; GP; Lung cancer; Lung cancer screening; Oncology; Primary care

\section{INTRODUCTION}

Lung cancer is a primary cancer of the lung and is classified histologically as small cell lung cancer (SCLC) or non-small cell lung cancer (NSCLC). The most common histological subtypes of NSCLC are adenocarcinoma, squamous cell and large cell cancers. 
Excluding non-melanoma skin cancers, lung cancer is the both the commonest type of cancer worldwide and the single largest cause of cancer mortality [1]. In England, lung cancer accounts for $13 \%$ of all cancers, following only breast and prostate cancer in terms of incidence [2], but is the leading cause of cancer deaths [3].

Improvements in early diagnosis and treatment have led to improved outcomes for many cancers. Since 1971, age-standardised 5-year survivals from breast cancer, prostate cancer and colorectal cancer in England and Wales have increased from $53 \%$ to $87 \%$ [4], $37 \%$ to $85 \%$ [5] and $24 \%$ to $59 \%$ respectively [6]. In contrast, the age-standardised 5-year survival for lung cancer has only increased from $5 \%$ to $10 \%$ [7]. Advances in the systemic treatment of advanced lung cancer with the use of tyrosine kinase inhibitors (TKIs) and immunotherapy have led to significant survival benefits for some patients [8-10]. The relatively infrequent expression of targets for these treatments and poor prognosis associated with advanced lung cancer have prevented these advances significantly impacting on overall survival. The introduction of stereotactic radiotherapy (SABR) has increased the radical treatment rate for early stage lung cancer without reducing surgical resection rates [11]. Lung cancer outcomes differ according to stage at diagnosis, with a 1-year survival of $81.7 \%$ for stage I and $15.5 \%$ for stage IV lung cancer in England and Wales [12]. Therefore, despite the substantial promise offered by novel therapies, achieving early diagnosis is likely to remain a crucial part of improving outcomes.

Most patients with lung cancer first present to their general practitioner (GP) [13-16]. Lung cancer often presents with symptoms that are very commonly encountered in primary care, making early diagnosis challenging. A large UKbased population study demonstrated that although cough is one of the most frequent symptoms of lung cancer, only $0.2 \%$ of patients who had a cough for 3 weeks were ultimately diagnosed with lung cancer [17]. The UK's National Cancer Diagnosis Audit reported that the median primary care interval (time from first presentation to referral) for lung cancer was 14 days, the second highest of 15 cancers reported. Prolonged primary care intervals of 60 and 90 days were experienced by $17.9 \%$ and $10.8 \%$ of patients respectively [18]. A third of patients diagnosed with lung cancer have attended their GP with symptoms attributable to their cancer three or more times before diagnosis [19]. Unfortunately, most lung cancers are still diagnosed at an advanced stage [20] and a third of lung cancers are diagnosed during emergency presentations [21]. The priority for most of these patients will be for prompt referral and investigation. Some patients with a high probability of malignant disease presenting with significant symptom burdens, rapid clinical deterioration or a high risk of acute hospital admission may benefit from synchronous referral to community palliative care services.

In common with other cancers, system factors are likely to affect the promptness of diagnosis. Some evidence suggests that settings that permit greater access to investigations are associated with improved survival [22]. Systems in which primary care practitioners have a strong role in rationing access to secondary care have been associated with poorer survival for the ten most common cancers, including lung cancer [23]. This suggests that the gate-keeping role of primary care practitioners may be a barrier to early diagnosis. This article is based on previously conducted studies and does not involve any new studies of human or animal subjects performed by any of the authors.

\section{RISK FACTORS AND EPIDEMIOLOGY}

Risk factors for the development of lung cancer include tobacco exposure, asbestos exposure, other occupational exposures, older age, male sex, chronic obstructive pulmonary disease (COPD), family history and air pollution.

Tobacco exposure remains the single greatest risk factor for developing lung cancer. In the UK, an estimated $71 \%$ of lung cancer deaths have been attributed to smoking and an additional $1 \%$ to environmental tobacco smoke ('second-hand smoke' or 'passive smoking') [24]. A Canadian study determined lifetime 
risks of lung cancer as $17.2 \%$ and $11.6 \%$ for male and female smokers respectively, compared to $1.3 \%$ and $1.4 \%$ for never-smokers [25]. The risk is increased by both the total quantity of tobacco to which an individual is exposed and the duration of time of which an individual remains a smoker [26]. The relative risk of lung cancer death is approximately 15 times higher in smokers compared to never-smokers, as demonstrated in a seminal cohort study [27]. Upon stopping smoking the relative risk of developing lung cancer declines rapidly; however, ex-smokers remain at an elevated level of risk compared to never-smokers [28].

Despite the well-understood link between smoking and lung cancer, clinicians should remain mindful that a significant proportion of lung cancers occur in patients who have never smoked, estimated at between $10 \%$ and $15 \%$ in one North American study [29].

Evidence of airway obstruction, typically associated with chronic obstructive pulmonary disease (COPD) and emphysema, is an independent risk factor for developing lung cancer, with a relative risk at least double that of matched populations without airway obstruction [30-32]. This remains significant even when factors such as over diagnosis of COPD are taken into account [33]. COPD and lung cancer have therefore been characterised as linked diseases, possibly sharing common pathological mechanisms [34].

After smoking, the working environment is the next most significant risk factor with $13 \%$ of lung cancers in the UK attributed to occupational exposures [24]. Asbestos accounts for a large proportion of these cases [35], though other occupational carcinogens include silica (e.g. through glass manufacture and sandblasting processes in textile manufacturing), diesel engine exhaust and aerosols inhaled whilst painting and welding [36]. Meanwhile, a further $8 \%$ of UK lung cancer cases have been attributed to air pollution [24].

While there are clear associations between these environmental and demographic factors and the incidence of lung cancer, it is important to recognise that lung cancer does still occur in younger patients and never-smokers. There is an increased prevalence of driver mutations, including epidermal growth factor receptor (EGFR) and anaplastic lymphoma kinase (ALK) mutations in patients with lung cancer who are younger and those who have never smoked. These driver mutations predict response to TKI therapy, which can lead to improved survival in patients with advanced disease $[9,10]$.

Lung cancer remains more common amongst men than women in the UK, with crude incidences of 77 and 66 per 100,000 population [37]. This is likely to be mediated strongly by differences in smoking behaviours, with $21.1 \%$ of males and $16.5 \%$ of females in the UK smoking in 2013 [38]. The incidence of lung cancer amongst men is declining globally, but is increasing amongst women in high income countries, reflecting patterns of increasing tobacco use in women and declining use in men [39].

Genetic factors play a role in the development of lung cancer [40] with a meta-analysis indicating that risk is $82 \%$ higher in those in whom a sibling has been diagnosed with lung cancer, after adjustment for smoking and other potential confounders [41].

Lung cancer incidence increases with age [42] and the median age of diagnosis in England and Wales was 72 years for women and 73 years for men in 2016 [12]. Although lung cancer is rare under the age of 40 , clinicians should not dismiss the possibility of lung cancer in younger patients.

\section{SYMPTOMS AND SIGNS}

The referral recommendations from the National Institute for Health and Care Excellence (NICE) are outlined in Box 1 [43]. This guidance was updated in 2015 with new recommendations that GPs refer all patients over age 40 years with unexplained haemoptysis and that consideration be given to plain chest X-ray (CXR) for patients with thrombocytosis and/or appetite loss. 
Box 1: Recommendations from NICE guideline [NG12] suspected cancer: recognition and referral [43] Refer people using a suspected cancer pathway referral (for appointment within 2 weeks) for lung cancer if they:

- Have chest X-ray findings that suggest lung cancer or

- Are aged 40 and over with unexplained haemoptysis

Offer an urgent chest X-ray (to be performed within 2 weeks) to assess for lung cancer in people aged 40 and over if they have 2 or more of the following unexplained symptoms, or if they have ever smoked and have 1 or more of the following unexplained symptoms:

- Cough

- Fatigue

- Shortness of breath

- Chest pain

- Weight loss

- Appetite loss

Consider an urgent chest X-ray (to be performed within 2 weeks) to assess for lung cancer in people aged 40 and over with any of the following:

- Persistent or recurrent chest infection

- Finger clubbing

- Supraclavicular lymphadenopathy or persistent cervical lymphadenopathy

- Chest signs consistent with lung cancer

- Thrombocytosis

The earliest stage of lung cancer is often not associated with any symptoms. The most common symptoms associated with lung cancer tend to be both common in benign presentations in the community and particularly amongst smokers. Therefore the discriminative utility of most of these symptoms in isolation is low. Positive predictive values (PPVs) for different symptoms of lung cancer, both alone and in combination, have been determined from a case-control study and are presented in Fig. 1. Importantly PPVs for each symptom are higher in smokers and those over the age of 70 years [44]. With the highest PPV of $2.4-7.5 \%$ [45], unexplained haemoptysis always warrants further investigation. Haemoptysis, however, is a feature of only about a fifth of lung cancers $[46,47]$, so the absence of this symptom should not provide reassurance.

While guidelines have streamlined access to diagnosis for some, concern has been raised that this approach might prioritise patients with classical presentations, such as haemoptysis, at the expense of those with symptoms which reflect less advanced disease and would therefore have the most to gain from early diagnosis [13]. In fact, in 2013 only $28 \%$ of lung cancer cases in England were diagnosed through the country's '2-week-wait' urgent referral pathway. In many cases appropriately urgent action may have occurred outside the 2 -week-wait pathway, for example through automatic referral following a suspicious CXR or through routine surveillance for pulmonary nodules. Although declining as a proportion, diagnoses following emergency presentations remained the commonest route of diagnosis at 35\% [48]. Such diagnoses are associated with the poorest outcomes, although the reasons for this are likely to be complex and probably include the poorer performance status, more advanced disease and greater levels of socio-economic deprivation of patients who present in this way [49].

In order to reduce the time intervals between patients experiencing symptoms and presenting to their GP, significant efforts have been made to improve public awareness. Evaluations of England's 'Be Clear on Cancer' campaign have suggested the programme contributed to encouraging increases in presentations to primary care with prolonged cough and an increase in the proportions diagnosed with early stage lung cancer [50, 51]. A longer-term assessment, however, has suggested that such campaigns require sustained commitment in order to maximise their impact [52]. In Australia, a cluster randomised trial of a complex intervention which included a public awareness campaign showed no reduction in the interval between symptoms and diagnosis [53], although the authors speculate that the intervention may not have achieved the breadth of media coverage required to show an effect.

A simple risk assessment tool has been developed which can generate positive predictive values for one symptom or two symptoms 


\begin{tabular}{|c|c|c|c|c|c|c|c|c|c|}
\hline $\begin{array}{l}\text { 호 } \\
\text { 오 }\end{array}$ & 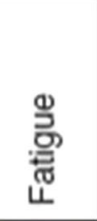 & 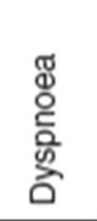 & 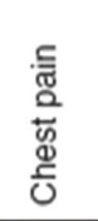 & 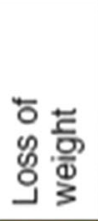 & 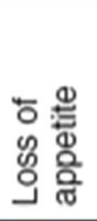 & 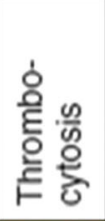 & 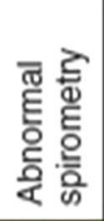 & 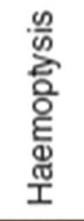 & \\
\hline $\begin{array}{c}\mathbf{0 . 4 0} \\
0.3, \\
0.5 \\
\end{array}$ & $\begin{array}{l}\mathbf{0 . 4 3} \\
0.3 \\
0.6 \\
\end{array}$ & $\begin{array}{l}\mathbf{0 . 6 6} \\
0.5, \\
0.8 \\
\end{array}$ & $\begin{array}{l}0.82 \\
0.6, \\
1.1 \\
\end{array}$ & $\begin{array}{l}1.1 \\
0.8, \\
1.6 \\
\end{array}$ & $\begin{array}{c}\mathbf{0 . 8 7} \\
0.6 \\
1.3 \\
\end{array}$ & $\begin{array}{l}1.6 \\
0.8, \\
3.1 \\
\end{array}$ & $\begin{array}{l}1.6 \\
0.9 \\
2.9 \\
\end{array}$ & $\begin{array}{l}2.4 \\
1.4, \\
4.1 \\
\end{array}$ & $\begin{array}{l}\text { PPV as a single } \\
\text { symptom }\end{array}$ \\
\hline \multirow[t]{9}{*}{$\begin{array}{l}0.4 \\
0.8\end{array}$} & $\begin{array}{l}\mathbf{0 . 6 3} \\
0.5 \\
0.9\end{array}$ & $\begin{array}{l}\mathbf{0 . 7 9} \\
0.6 \\
1.0\end{array}$ & $\begin{array}{l}\mathbf{0 . 7 6} \\
0.6 \\
1.0\end{array}$ & $\begin{array}{l}\mathbf{1 . 8} \\
1.1 \\
2.9\end{array}$ & $\begin{array}{l}\mathbf{1 . 6} \\
0.9 \\
2.7\end{array}$ & $\begin{array}{l}2.0 \\
1.1 \\
3.5\end{array}$ & $\begin{array}{l}1.2 \\
0.6 \\
2.6\end{array}$ & $\begin{array}{l}2.0 \\
1.1 \\
3.5\end{array}$ & Cough \\
\hline & $\begin{array}{l}\mathbf{0 . 5 7} \\
0.4 \\
0.9\end{array}$ & $\begin{array}{l}\mathbf{0 . 8 9} \\
0.6, \\
0.3\end{array}$ & $\begin{array}{l}\mathbf{0 . 8 4} \\
0.5 \\
1.3\end{array}$ & $\begin{array}{l}1.0 \\
0.6 \\
1.7\end{array}$ & $\begin{array}{l}1.2 \\
0.7 \\
2.1\end{array}$ & 1.8 & 4.0 & 3.3 & Fatigue \\
\hline & & 0.88 & $\begin{array}{l}1.2 \\
0.9 \\
1.8\end{array}$ & $\begin{array}{l}2.0 \\
1.2 \\
3.8\end{array}$ & $\begin{array}{l}2.0 \\
1.2 \\
3.8\end{array}$ & 2.0 & 2.3 & 4.9 & Dyspnœea \\
\hline & & & $\begin{array}{l}0.95 \\
0.7 \\
1.4\end{array}$ & $\begin{array}{l}\mathbf{1 . 8} \\
1.0 \\
3.4\end{array}$ & $\begin{array}{l}1.8 \\
0.9 \\
3.9\end{array}$ & 2.0 & 1.4 & 5.0 & Chest pain \\
\hline & & & & $\begin{array}{l}1.2 \\
0.7 \\
2.3\end{array}$ & $\begin{array}{l}2.3 \\
1.2 \\
4.4\end{array}$ & 6.1 & 1.5 & 9.2 & Loss of weight \\
\hline & & & & & 1.7 & 0.9 & 2.7 & $>10$ & Loss of appetite \\
\hline & & & & & & & 3.6 & $>10$ & Thrombocytosis \\
\hline & & & & & & & & $>10$ & $\begin{array}{l}\text { Abnormal } \\
\text { spirometry }\end{array}$ \\
\hline & & & & & & & & 17 & Haemoptysis \\
\hline
\end{tabular}

Fig. 1 Positive predictive values (\%) for lung cancer for individual risk markers, and for pairs of risk markers in combination (against a background risk of 0.18\%). (1) The top row (bold) gives the PPV for an individual feature. The cells along the diagonal relate to the PPV when the same feature has been reported twice. Other cells show the PPV when a patient has two different features. (2) The top figure in each cell is the PPV. It has only been calculated when a minimum of ten cases had the feature or

in combination stratified for smokers and nonsmokers [54]. Assessment of this tool (Fig. 1) has shown that, when used, it is associated with combination of features. The two other figures are the 95\% CIs for the PPV. These have not been calculated when any cell in the $2 \times 2$ table was below 10. (3) The yellow shading is when the PPV is above $1 \%$. The amber shading is when the PPV is above $2 \%$. The red shading is for PPVs above $5.0 \%$. Reprinted by permission from Springer Nature Customer Service Centre GmbH: Springer Nature. Ref. [54]

increased investigations such as CXR, urgent referrals and lung cancer diagnoses [55]. Two algorithms have also been created which 
incorporate symptoms as well as other risk factors to generate risk scores $[17,56]$.

Positive examination findings are usually only associated with advanced disease, so examination will typically be unremarkable. Since an individual GP will, on average, encounter only one new case of lung cancer each year [57], the prospects of identifying lung cancer through rare signs such as hypertrophic pulmonary osteoarthropathy and Horner's syndrome are exceedingly unlikely. In clinical practice, patient and physician intuition of the possibility of serious underlying disease is probably much more important [58]. Given that the 'risk threshold' NICE has adopted for further investigation or referral for suspected cancer is 3\% [43], GPs should feel empowered to refer patients at relatively low levels of risk [59].

In situations in which a decision for further follow-up or investigation has not been made, GPs should advise their patients to represent if symptoms fail to resolve or new symptoms develop. Although little evidence exists for the effectiveness of 'safety netting' [60], the experience of significant event audit suggests it is an important strategy to reduce the risk of delayed diagnosis [61]. Safety netting is recommended as part of the NICE guidelines for suspected cancer referral [43] and GPs should be aware that there is a medico-legal expectation that safety netting is adequately undertaken and documented [62].

\section{INVESTIGATION OF SUSPECTED LUNG CANCER}

The first-line investigation of suspected lung cancer remains the CXR. CXR has the advantages of being cheap and accessible [58], with a low radiation dose of $0.02 \mathrm{mSv}$ equivalent to 3 days of natural background radiation [63]. Unfortunately, CXR has a significant false negative rate, with a sensitivity of approximately 75-80\% [64-67]. One study has reported that $10 \%$ of the CXRs of lung cancer patients were initially reported as normal, with a further 13\% which were reported as abnormal but with no suspicion of lung cancer [64]. Despite its limitations, evidence suggests that strategies to increase CXR uptake can yield improvements in referral rates and possibly improve early detection of lung cancer [51, 68].

Previous guidance that all patients with radiologically demonstrated community-acquired pneumonia should have a repeat CXR after 6 weeks to confirm resolution has been refined to include only those at highest risk of malignancy, such as smokers and those aged over 50 years [69]. Evidence from a populationbased cohort study provides some reassurance that such an approach is reasonable, given that only one in 57 patients who did have lung cancer 1 year following their pneumonia were under the age of 50 and that overall only $40 \%$ of patients attended for a repeat CXR within 90 days [70].

Computed tomography (CT) scans of the chest are much more sensitive than CXR, although the majority of available evidence relates to screening contexts, rather than the investigation of symptomatic patients. In the US National Lung Screening Trial (NLST), low dose CT (LDCT) yielded sensitivity and specificity of $93.8 \%$ and $73.4 \%$ compared to $73.5 \%$ and $91.3 \%$ for CXR, respectively [71]. In most contexts conventional CT continues to be used for symptomatic investigation. NICE recommends contrast-enhanced CT of the thorax including also the liver and adrenal glands [72]. This is usually arranged from secondary care following an urgent referral from a primary care physician for suspected lung cancer, although in some regions GPs may have direct access to CT. In the UK the National Optimal Lung Pathway [73] has set out standards for lung cancer service providers to improve the quality and efficiency of pathways for patients with suspected lung cancer including the timing of investigations. This pathway aims to reduce the time between referral, CT scan and review by respiratory physician with an interest in lung cancer.

Access to and use of CT varies greatly across different health systems. Fewer CT scans are performed in the UK than other Western European countries [74]. Higher rates of CT use in the US have been identified as a concern given the resulting radiation exposure [75]. LDCT uses an estimated radiation dose of $2 \mathrm{mSv}$, compared 
to $7 \mathrm{mSv}$ from conventional CT [76]. Increased availability of LDCT in the future could help reduce the total radiation exposure.

Widening access to urgent CT scans for GPs (sometimes termed 'direct access') has been suggested as a means to improve early stage diagnosis [77]. In Denmark, a country where GPs serve a similar gate-keeping role to their counterparts in the UK, a cluster-randomised controlled trial found that giving GPs access to LDCT to investigate possible lung cancer led to no statistically significant decrease to the time to diagnosis. Following adjustment for non-engagement in the intervention group it was found that patients in the control group were at a higher risk of experiencing a long diagnostic interval [78]. The relatively low levels of engagement, which reached only around half of eligible GPs, might suggest that achieving uptake of direct access investigations requires a broader shift in practice rather than simply permitting their use.

Patients with haemoptysis have also routinely been investigated with bronchoscopy to exclude lung cancer. Diagnostic evaluations of CT have suggested that bronchoscopy can be omitted in most cases if malignancy is not identified on CT $[79,80]$.

\section{SCREENING}

The US Prostate, Lung, Colorectal and Ovarian (PLCO) screening trial has provided the largest and most conclusive body of evidence that screening asymptomatic populations with CXR does not reduce lung cancer mortality [81]. The US National Lung Screening Trial (NLST) demonstrated a $20 \%$ reduction in lung cancer mortality with annual LDCT in an asymptomatic high-risk population [82]. The US Preventative Task Force (USPSTF) has since recommended annual screening with LDCT for those aged 55-80 who have a 30-pack-year smoking history and are current smokers or have smoked within the last 15 year [83]. Uptake of screening in the USA, however, remains low $[84,85]$. This may be due to the lack of a fully co-ordinated national approach [86]. The European Union position statement on lung cancer screening set out specific actions that were required before the widespread implementation of lung cancer screening [87]. The UK National Screening Committee (NSC) does not currently recommend lung cancer screening. The NSC is expected to review this decision following the publication of final results from the Dutch-Belgian NELSON trial [88]. These results were presented at the International Association for the Study of Lung Cancer (IASLC) World Conference on Lung cancer (WCLC) 2018 in Toronto. The presented data demonstrated a significant reduction in lung cancer mortality in the screened male population. There was a greater reduction in mortality in the screened female population, but this cohort was smaller and this difference did not reach significance. Combined population data and overall mortality data has not yet been presented.

Potential harms of LDCT screening must be weighed against any potential benefits. These include increased exposure to ionising radiation [89], invasive investigation and follow-up for benign changes and over diagnosis of cancers which if left undiscovered would not have affected patients [90-93]. The experience of the Danish Lung Cancer screening trial suggests that the problem of overdiagnosis in particular could be greater than that previously estimated in the National Lung Cancer Screening Trial [94]. Unfortunately, evidence from the USA suggests that in discussing lung cancer screening, clinicians' communication of the possible harms is very limited [95]. These harms are reduced by targeting screening programmes on the population at highest risk of lung cancer.

Analysis of the Surveillance, Epidemiology and End Results (SEER) database has shown that only $26.7 \%$ of patients with lung cancer in the USA would have been eligible for LDCT screening by NLST criteria [96]. The use of composite risk prediction tools, such as The Liverpool Lung Project [97] or PLCO $_{\mathrm{M} 2012}$ models [98], may better identify the high-risk population and increase the proportion of lung cancers that may be detected by screening. A significant proportion of patients who go on to develop lung cancer will not have been eligible for LDCT screening. Of those who are eligible, 
some will choose not to undergo screening and the possibility remains of developing lung cancer between annual LDCT screening (interval cancers). It is therefore likely that the majority of lung cancers will continue to be diagnosed by appropriate investigation of symptomatic patients by vigilant clinicians.

\section{CONCLUSIONS}

Improving early diagnosis of lung cancer is crucial to improving outcomes. The majority of patients with lung cancer present to their GP with symptoms and the early identification of lung cancer remains a key challenge. The low cost, safety and availability of CXR justify a low threshold for use of this investigation by GPs. In the context of patients with ongoing symptoms and/or significant risk factors, however, clinicians should be aware of the imperfect sensitivity of CXR and exercise appropriate vigilance. Depending on the level of risk, strategies including safety netting, planning a repeat CXR after an appropriate interval or an urgent referral for further investigation such as CT or secondary care assessment may be reasonable.

While screening with LDCT may offer improved outcomes to the highest-risk populations, most patients who develop lung cancer will not be eligible for screening meaning that the role of GPs in recognising symptomatic disease will remain crucial.

\section{ACKNOWLEDGEMENTS}

Funding. No funding or sponsorship was received for this study or publication of this article.

Authorship. All named authors meet the International Committee of Medical Journal Editors (ICMJE) criteria for authorship for this article, take responsibility for the integrity of the work as a whole, and have given their approval for this version to be published.
Disclosures. Stephen H. Bradley is funded by the multi-institutional CanTest Collaborative which is funded by Cancer Research UK (C8640/A23385). Richard D. Neal is an Associate Director of the multi-institutional CanTest Collaborative which is funded by Cancer Research UK (C8640/A23385). Martyn P.T. Kennedy has nothing to disclose.

Compliance with Ethical Guidelines. This article is based on previously conducted studies and does not involve any new studies of human or animal subjects performed by any of the authors.

Open Access. This article is distributed under the terms of the Creative Commons Attribution-NonCommercial 4.0 International License (http://creativecommons.org/licenses/ by-nc/4.0/), which permits any noncommercial use, distribution, and reproduction in any medium, provided you give appropriate credit to the original author(s) and the source, provide a link to the Creative Commons license, and indicate if changes were made.

\section{REFERENCES}

1. Ferlay J, Soerjomataram I, Dikshit R, et al. Cancer incidence and mortality worldwide: sources, methods and major patterns in GLOBOCAN 2012. Int J Cancer. 2015;136(5):E359-86.

2. Cancer registration statistics, England, 2016 Office for National Statistics 2018. https://www.ons.gov. uk/peoplepopulationandcommunity/healthandsocial care/conditionsanddiseases/bulletins/cancerregistra tionstatisticsengland/final2016. Accessed 17 Sept 2018.

3. All data related to Deaths registered in England and Wales: 2017: Office for National Statistics. 2018. https://www.ons.gov.uk/peoplepopulationandcom munity/birthsdeathsandmarriages/deaths/bulletins/ deathsregistrationsummarytables/2017/relateddata. Accessed 17 Sept 2018.

4. Breast cancer survival statistics: Cancer Research UK. 2014. https://www.cancerresearchuk.org/healthprofessional/cancer-statistics/statistics-by-cancertype/breast-cancer/survival\#heading-Two. Updated 27 Nov 2014, 29 Sept 2018. 
5. Prostate cancer survival statistics: Cancer Research UK. https://www.cancerresearchuk.org/health-profes sional/cancer-statistics/statistics-by-cancer-type/pro state-cancer/survival\#heading-Two. Updated 9 Dec 2014. 29 Sept 2018.

6. Bowel cancer survival statistics: Cancer Research UK. 2014. https://www.cancerresearchuk.org/healthprofessional/cancer-statistics/statistics-by-cancer-type/ bowel-cancer/survival\#heading-Two. Updated 1 Dec 2014, 29 Sept 2018.

7. Lung cancer survival statistics: Cancer Research UK. http://www.cancerresearchuk.org/health-professional/ cancer-statistics/statistics-by-cancer-type/lung-cancer/ survival. Accessed 16 May 2018.

8. Fukuoka M, Wu Y-L, Thongprasert S, et al. Biomarker analyses and final overall survival results from a phase III, randomized, open-label, first-line study of gefitinib versus carboplatin/paclitaxel in clinically selected patients with advanced nonsmall-cell lung cancer in Asia (IPASS). J Clin Oncol. 2011;29(21):2866-74.

9. Rosell R, Carcereny E, Gervais R, et al. Erlotinib versus standard chemotherapy as first-line treatment for European patients with advanced EGFR mutation-positive non-small-cell lung cancer (EURTAC): a multicentre, open-label, randomised phase 3 trial. Lancet Oncol. 2012;13(3):239-46.

10. Solomon BJ, Mok T, Kim D-W, et al. First-line crizotinib versus chemotherapy in ALK-positive lung cancer. N Engl J Med. 2014;371(23):2167-77.

11. Palma D, Visser O, Lagerwaard FJ, Belderbos J, Slotman BJ, Senan S. Impact of introducing stereotactic lung radiotherapy for elderly patients with stage I non-small-cell lung cancer: a populationbased time-trend analysis. J Clin Oncol. 2010;28(35):5153-9.

12. NCLA annual report 2017: Royal College of Physicians. 2018. https://www.rcplondon.ac.uk/projects/ outputs/nlca-annual-report-2017. Accessed 17 Sept 2018.

13. Hamilton W. Five misconceptions in cancer diagnosis. Br J Gen Pract. 2009;59(563):441-7.

14. Demagny L, Holtedahl K, Bachimont J, Thorsen T, Letourmy A, Bungener M. General practitioners' role in cancer care: a French-Norwegian study. BMC Res Notes. 2009;2(1):200.

15. Tørring ML, Frydenberg M, Hansen RP, Olesen F, Vedsted P. Evidence of increasing mortality with longer diagnostic intervals for five common cancers: a cohort study in primary care. Eur J Cancer. 2013;49(9):2187-98.
16. Ewing $\mathrm{M}$, Naredi $\mathrm{P}$, Nemes $\mathrm{S}$, Zhang C, Månsson J. Increased consultation frequency in primary care, a risk marker for cancer: a case-control study. Scand J Prim Health Care. 2016;34(2):205-12.

17. Iyen-Omofoman B, Tata LJ, Baldwin DR, Smith CJ, Hubbard RB. Using socio-demographic and early clinical features in general practice to identify people with lung cancer earlier. Thorax. 2013;68(5):451-9.

18. Swann R, McPhail S, Witt J, et al. Diagnosing cancer in primary care: results from the National Cancer Diagnosis Audit. Br J Gen Pract. 2018;68(666): e63-72.

19. Lyratzopoulos G, Abel GA, McPhail S, Neal RD, Rubin GP. Measures of promptness of cancer diagnosis in primary care: secondary analysis of national audit data on patients with 18 common and rarer cancers. Br J Cancer. 2013;108:686.

20. McPhail S, Johnson S, Greenberg D, Peake M, Rous B. Stage at diagnosis and early mortality from cancer in England. Br J Cancer. 2015;112 (Suppl 1):S108-15.

21. National Cancer Intelligence Network. Routes to diagnosis. London: Public Health England. 2018. https://data.healthdatainsight.org.uk/apps/routes_ to_diagnosis/route_breakdown/. Accessed 27 Oct 2018.

22. Rose PW, Rubin G, Perera-Salazar R, et al. Explaining variation in cancer survival between 11 jurisdictions in the International Cancer Benchmarking Partnership: a primary care vignette survey. BMJ Open. 2015;5(5):e007212. https://doi.org/10.1136/ bmjopen-2014-007212.

23. Vedsted P, Olesen F. Are the serious problems in cancer survival partly rooted in gatekeeper principles? An ecologic study. Br J Gen Pract. 2011;61(589):e508-12.

24. Brown KF, Rumgay H, Dunlop C, et al. The fraction of cancer attributable to modifiable risk factors in England, Wales, Scotland, Northern Ireland, and the United Kingdom in 2015. Br J Cancer. 2018;118(8):1130-41.

25. Villeneuve P, Mao Y. Lifetime probability of developing lung cancer. Can J Public Health. 1994;85(6):385-8.

26. Lubin JH, Caporaso NE. Cigarette smoking and lung cancer: modeling total exposure and intensity. Cancer Epidemiol Biomark Prev. 2006;15(3):517-23.

27. Doll R, Peto R, Boreham J, Sutherland I. Mortality from cancer in relation to smoking: 50 years observations on British doctors. $\mathrm{Br} \mathrm{J}$ Cancer. 2005;92:426. 
28. Peto J. That lung cancer incidence falls in exsmokers: misconceptions $2 . \mathrm{Br} \mathrm{J}$ Cancer. 2011;104(3):389.

29. Pelosof L, Ahn C, Gao A, et al. Proportion of neversmoker non-small cell lung cancer patients at three diverse institutions. J Natl Cancer Inst. 2017;109(7):295.

30. Mannino DM, Aguayo SM, Petty TL, Redd SC. Low lung function and incident lung cancer in the United States: data from the first National Health and Nutrition Examination Survey follow-up. Arch Intern Med. 2003;163(12):1475-80.

31. Skillrud DM, Offord KP, Miller R. Higher risk of lung cancer in chronic obstructive pulmonary disease: a prospective, matched, controlled study. Ann Intern Med. 1986;105(4):503-7.

32. Kiri VA, Soriano JB, Visick G, Fabbri LM. Recent trends in lung cancer and its association with COPD: an analysis using the UK GP Research Database. Prim Care Respir J. 2009;19:57.

33. Young RP, Duan F, Chiles C, et al. Airflow limitation and histology shift in the National Lung Screening Trial. The NLST-ACRIN cohort substudy. Am J Respir Crit Care Med. 2015;192(9): 1060-7.

34. Durham AL, Adcock IM. The relationship between COPD and lung cancer. Lung Cancer. 2015;90(2): 121-7.

35. McCormack V, Peto J, Byrnes G, Straif K, Boffetta P. Estimating the asbestos-related lung cancer burden from mesothelioma mortality. $\mathrm{Br} \mathrm{J}$ Cancer. 2012;106:575.

36. Brown T, Darnton A, Fortunato L, Rushton L. Occupational cancer in Britain. $\mathrm{Br} \mathrm{J}$ Cancer. 2012;107:S56.

37. Cancer Research UK. Lung cancer statistics. 2018. https://www.cancerresearchuk.org/healthprofessional/cancer-statistics/statistics-by-cancertype/lung-cancer. Accessed 28 June 2018.

38. Cancer Research UK. Tobacco statistics. 2014. https:// www.cancerresearchuk.org/health-professional/can cer-statistics/risk/tobacco\#heading-One. Accessed 6 Sept 2018.

39. Bray F, Jemal A, Grey N, Ferlay J, Forman D. Global cancer transitions according to the Human Development Index (2008-2030): a population-based study. Lancet Oncol. 2012;13(8):790-801.

40. Schwartz AG, Ruckdeschel JC. Familial lung cancer. Am J Respir Crit Care Med. 2006;173(1):16-22.
41. Coté ML, Liu M, Bonassi S, et al. Increased risk of lung cancer in individuals with a family history of the disease: a pooled analysis from the International Lung Cancer Consortium. Eur J Cancer. 2012;48(13):1957-68.

42. Kamo K, Katanoda K, Matsuda T, Marugame T, Ajiki $\mathrm{W}$, Sobue T. Lifetime and age-conditional probabilities of developing or dying of cancer in Japan. Jpn J Clin Oncol. 2008;38(8):571-6.

43. National Institute for Health and Care Excellence. NICE guideline [NG12]. Suspected cancer: recognition and referral 2015. https://www.nice.org.uk/ guidance/ng12. Updated July 2017, 13th Aug 2018.

44. Hamilton W. Towards earlier diagnosis of cancer in primary care: a population-based case-control study of colorectal, lung and prostate cancer. MD thesis, Bristol. 2005.

45. Shim J, Brindle L, Simon M, George S. A systematic review of symptomatic diagnosis of lung cancer. Fam Pract. 2014;31(2):137-48.

46. Hamilton W, Peters TJ, Round A, Sharp D. What are the clinical features of lung cancer before the diagnosis is made? A population based case-control study. Thorax. 2005;60(12):1059-65.

47. Walter FM, Rubin G, Bankhead C, et al. Symptoms and other factors associated with time to diagnosis and stage of lung cancer: a prospective cohort study. Br J Cancer. 2015;112:S6.

48. National Cancer Intelligence Network. Routes to diagnosis 2016-2013 workbook. London: NCIN. 2015. http://www.ncin.org.uk/publications/routes_ to_diagnosis. Accessed 14 Aug 2018.

49. Beckett P, Tata LJ, Hubbard RB. Risk factors and survival outcome for non-elective referral in nonsmall cell lung cancer patients-analysis based on the National Lung Cancer Audit. Lung Cancer. 2014;83(3):396-400.

50. Ironmonger L, Ohuma E, Ormiston-Smith N, Gildea C, Thomson CS, Peake MD. An evaluation of the impact of large-scale interventions to raise public awareness of a lung cancer symptom. Br J Cancer. 2014;112:207.

51. Kennedy MPT, Cheyne L, Darby M, et al. Lung cancer stage-shift following a symptom awareness campaign. Thorax. 2018;73(12):1128-36.

52. Peake M. National cancer registration and analysis service. Be clear on cancer: regional and national lung cancer awareness campaigns 2011 to 2014. Final evaluation results-executive headlines. London: Public Health England. 2018. Available ncin. org.uk/view?rid=3632. Accessed 27 Nov 2018. 
53. Emery JD, Gray V, Walter FM, et al. The improving rural cancer outcomes trial: a cluster-randomised controlled trial of a complex intervention to reduce time to diagnosis in rural cancer patients in Western Australia. Br J Cancer. 2017; 117:1459.

54. Hamilton W. The CAPER studies: five case-control studies aimed at identifying and quantifying the risk of cancer in symptomatic primary care patients. Br J Cancer. 2009;101:S80.

55. Hamilton W, Green T, Martins T, Elliott K, Rubin G, Macleod U. Evaluation of risk assessment tools for suspected cancer in general practice: a cohort study. Br J Gen Pract. 2013;63(606):e30-6.

56. Hippisley-Cox J, Coupland C. Identifying patients with suspected lung cancer in primary care: derivation and validation of an algorithm. Br J Gen Pract. 2011;61(592):e715-23.

57. Neal RD, Hamilton W, Rogers TK. Lung cancer. BMJ. 2014;349:g6560.

58. Hamilton W. Cancer diagnosis in primary care. $\mathrm{Br} \mathrm{J}$ Gen Pract. 2010;60(571):121-8.

59. Barraclough K. New NICE guidance on referral for cancer. BMJ. 2015;351:h3640.

60. Nicholson BD, Mant D, Bankhead C. Can safetynetting improve cancer detection in patients with vague symptoms? BMJ. 2016;355:i5515.

61. Mitchell ED, Rubin G, Macleod U. Understanding diagnosis of lung cancer in primary care: qualitative synthesis of significant event audit reports. Br J Gen Pract. 2013;63(606):e37-46.

62. Jarvis S. Playing it safe-safety netting advice. 2016. https://mdujournal.themdu.com/issue-archive/issue4/playing-it-safe-safety-netting-advice. Updated 11 Mar 2016. 19 Sept 2018.

63. Public Health England. Patient dose information: guidance. 2008. https://www.gov.uk/government/ publications/medical-radiation-patient-doses/patientdose-information-guidance. Accessed 27 Nov 2018.

64. Stapley S, Sharp D, Hamilton W. Negative chest $\mathrm{X}$-rays in primary care patients with lung cancer. $\mathrm{Br}$ J Gen Pract. 2006;56(529):570-3.

65. Fernandez V, Alonso JL, Munuera L, et al. Analysis of lung cancer cases diagnosed in an internal medicine department: from January 2001 to September 2006. An Sist Sanit Navar. 2007;30(3):353-62.

66. Bjerager M, Palshof T, Dahl R, Vedsted P, Olesen F. Delay in diagnosis of lung cancer in general practice. Br J Gen Pract. 2006;56(532):863-8.
67. Mitchell E, Macleod U, Rubin G. Report for the national awareness and early diagnosis initiative. Cancer in primary care. An analysis of significant event audits (SEA) for cancer diagnosis: 2008-2009. Department of Health National Cancer Action Team and North of England Cancer Network. 2009. http://www.necn.nhs.uk/wp-content/uploads/2012/ 10/AnalysisofSEAforcancerdiagnosis-Finalreport.pdf. Accessed 27 Nov 2018.

68. Athey VL, Suckling RJ, Tod AM, Walters SJ, Rogers TK. Early diagnosis of lung cancer: evaluation of a community-based social marketing intervention. Thorax. 2012;67(5):412-7.

69. Lim WS, Baudouin SV, George RC, et al. BTS guidelines for the management of community acquired pneumonia in adults: update 2009. Thorax. 2009;64(Suppl 3):1-55.

70. Tang KL, Eurich DT, Minhas-Sandhu JK, Marrie TJ, Majumdar SR. Incidence, correlates, and chest radiographic yield of new lung cancer diagnosis in 3398 patients with pneumonia. Arch Intern Med. 2011;171(13):1193-8.

71. National Lung Screening Trial Research Team. Results of initial low-dose computed tomographic screening for lung cancer. $N$ Engl $J$ Med. 2013;368(21):1980-91.

72. National Institute for Health and Care Excellence. NICE guideline [CG121]. Lung cancer: diagnosis and management. 2011. https://www.nice.org.uk/ guidance/cg121/chapter/1-Guidance. Accessed 14 Aug 2018.

73. Lung Clinical Expert Group. National optimal lung cancer pathway. 2017. https://www.cancerresearch uk.org/sites/default/files/national_optimal_lung_ pathway_aug_2017.pdf. Accessed 27 Nov 2018.

74. Healthcare resource statistics-technical resources and medical technology. Eurostat; 2017. http://ec. europa.eu/eurostat/statistics-explained/index.php? oldid=280129. Accessed 14 Aug 2018.

75. Brenner DJ, Hall EJ. Computed tomography-an increasing source of radiation exposure. $\mathrm{N}$ Engl J Med. 2007;357(22):2277-84.

76. Larke FJ, Kruger RL, Cagnon $\mathrm{CH}$, et al. Estimated radiation dose associated with low-dose chest CT of average-size participants in the national lung screening trial. Am J Roentgenol. 2011;197(5): 1165-9.

77. Millett D. Why GPs need better access to diagnostic cancer scans. GP. 2014. https://www.gponline.com/ why-gps-need-better-access-diagnostic-cancer-scans/ cancer/article/1322828. 
78. Guldbrandt LM, Rasmussen RR, Ramussen F, Vedsted P. Implementing direct access to low-dose computed tomography in general practice-method, adaption and outcome. PLoS One. 2014;9(11):1-9.

79. Arooj P, Bredin E, Henry MT, et al. Bronchoscopy in the investigation of outpatients with hemoptysis at a lung cancer clinic. Respir Med. 2018;139:1-5.

80. Kennedy MP, Arooj P, Henry MT. Bronchoscopy is not required in patients being investigated for hemoptysis at a rapid access cancer clinic with normal CT scan. Chest. 2018;154(2):465-6.

81. Oken MM, Hocking WG, Kvale PA, et al. Screening by chest radiograph and lung cancer mortality. The prostate, lung, colorectal, and ovarian (PLCO) randomized trial. J Am Med Assoc. 2011;306(17): 1865-73.

82. National Lung Screening Trial Research Team, Aberle DR, Adams AM, et al. Reduced lung-cancer mortality with low-dose computed tomographic screening. N Engl J Med. 2011;365(5):395-409.

83. Moyer VA. On behalf of the USPSTF. Screening for lung cancer: US Preventive Services Task Force recommendation statement. Ann Intern Med. 2014;160(5):330-8.

84. Pham D, Bhandari S, Oechsli M, Pinkston CM, Kloecker GH. Lung cancer screening rates: data from the lung cancer screening registry. J Clin Oncol. 2018;36(no. 15_suppl):6504.

85. Jemal A, Fedewa SA. Lung cancer screening with low-dose computed tomography in the United States-2010 to 2015. JAMA Oncol. 2017;3(9):1278-81.

86. Baldwin DR, ten Haaf K, Rawlinson J, Callister MEJ. Low dose CT screening for lung cancer. BMJ. 2017;359:j5742.

87. Oudkerk M, Devaraj A, Vliegenthart R, et al. European position statement on lung cancer screening. Lancet Oncol. 2017;18(12):e754-66.

88. $\mathrm{Xu} \mathrm{DM}$, Gietema $\mathrm{H}$, de Koning $\mathrm{H}$, et al. Nodule management protocol of the NELSON randomised lung cancer screening trial. Lung Cancer. 2006;54(2):177-84.

89. Rampinelli C, De Marco P, Origgi D, et al. Exposure to low dose computed tomography for lung cancer screening and risk of cancer: secondary analysis of trial data and risk-benefit analysis. BMJ. 2017;356:j347.

90. Bach PB, Mirkin JN, Oliver TK, et al. Benefits and harms of CT screening for lung cancer: a systematic review. JAMA. 2012;307(22):2418-29.

91. Ruparel M, Quaife SL, Navani N, Wardle J, Janes SM, Baldwin DR. Pulmonary nodules and CT screening: the past, present and future. Thorax. 2016;71(4): 367-75.

92. Bach PB. Overdiagnosis in lung cancer: different perspectives, definitions, implications. Thorax. 2008;63(4):298-300.

93. ten Haaf $\mathrm{K}$, de Koning $\mathrm{HJ}$. Overdiagnosis in lung cancer screening: why modelling is essential. J Epidemiol Commun Health. 2015;69(11):1035-9.

94. Heleno B, Siersma V, Brodersen J. Estimation of overdiagnosis of lung cancer in low-dose computed tomography screening: a secondary analysis of the Danish lung cancer screening trial. JAMA Intern Med. 2018;178(10):1420-2.

95. Brenner AT, Malo TL, Margolis M, et al. Evaluating shared decision making for lung cancer screening. JAMA Intern Med. 2018;178(10):1311-6.

96. Pinsky PF, Berg CD. Applying the National Lung Screening Trial eligibility criteria to the US population: what percent of the population and of incident lung cancers would be covered? J Med Screen. 2012;19(3):154-6.

97. Cassidy A, Myles JP, van Tongeren M, et al. The LLP risk model: an individual risk prediction model for lung cancer. Br J Cancer. 2007;98:270.

98. Tammemägi MC, Katki HA, Hocking WG, et al. Selection criteria for lung-cancer screening. N Engl J Med. 2013;368(8):728-36. 